\title{
Build the Picture, Build the Plan: The Role of Control Room Displays in Team Sensemaking
}

\author{
Corey Fallon \\ Klein Associates Division of Applied Research Associates \\ cfallon@ara.com
}

\author{
Cynthia Dominguez \\ Klein Associates Division of Applied Research \\ cdominguez@ara.com
}

\begin{abstract}
Motivation - The researchers employed several interview methodologies to uncover themes for how submarine crews interact with each other and the control room technology to make sense of their environment. Research Approach - The interview methodologies employed include simulation, training and Team Sensemaking Critical Incident Method (SCIM) interviews. Findings/Design - The data suggests control room team members' understanding of the tactical picture and ability to support projection, were critical to success. Research Limitation/Implications - These findings are from an initial high level analysis on a subset of the total sample. Originality/Value - The findings are valuable because understanding how submarine teams make sense of their data and each others' input is necessary for supporting that behavior. Take away message - We will describe what we learned about team sensemaking in submarine environments, with a focus on how teams build their picture and plan and how technology supports those efforts.
\end{abstract}

\section{Keywords}

Team, sensemaking, submarine, control room, displays.

\section{INTRODUCTION}

Submarine control room crews work continuously to determine their position relative to nearby contacts, under rapidly changing conditions and with imperfect information. Submarine crews "drive without a windshield," as one former submarine commander described the experience-with the major difference being that a team of 10-15 people are working together to coordinate the driving effort (Dominguez, McKneely, \& Fallon, 2008). Our preliminary analysis of interviews with submarine command team officers revealed how safety is achieved through team interaction with each other and the control room technology. We examined how control room information displays support team sensemaking and identified several emerging themes that characterize how control room team members interact to build the picture and the plan.

\section{METHODS}

\section{Participants}

We conducted individual and team based interviews on command team members. For our training interviews we collected data from TRE Inspectors, Deputy Squadron Commanders, PCO Instructors, Training facility COs, Assistant COs and Junior Officer trainees. Participants were interviewed from both the Atlantic and Pacific fleets.

\section{Procedure}

The Team SCIMs were semi-structured knowledge elicitation exercises with a 4-person command team from one ship. The team was asked to recall a shared experience when they faced an uncertain situation that required team sensemaking. The knowledge elicitation exercise was based on this incident. The individual scenario based interviews were structured with a standard set of questions and based on a scenario developed by subject matter experts. We also conducted training interviews to understand command team training and how training can be improved to enhance team performance. These interviews focused on current training practices, and the state of teams today. The individual interviews have been transcribed and annotated using a data-derived set of codes. The resulting coded data are used to draw conclusions on how teams interact with each other and technology to make sense of their environment.

\section{PRELIMINARY FINDINGS}

These findings are from an initial high level analysis on a subset of the total sample. The final report will contain a more in depth analysis of the complete dataset. Deeper analysis on a larger and more representative sample may reveal additional themes and patterns not reported in this paper. Also, some of the findings in this paper may be modified in light of additional analysis. 


\section{Digital Plots Supporting Sensemaking and CDO Intervention Decisions}

Watch teams rely on digital plots to help fuse and display data about their surroundings. These plots are visual representations of the surrounding environment. They reflect the team's situation awareness and help to support team sensemaking because the plot data is processed and maintained by the team. In addition, the OOD can use the plot information to support his sensemaking.

The Command Duty Officer (CDO) is responsible for continuously maintaining the picture and engages in the team sensemaking process when necessary. To meet both responsibilities the CDO develops a mental picture of the situation independent of his team and evaluates his team's assessment of the situation by comparing their assessment to his own. The digital plots can serve as a valuable decision aid for the CDO because they provide a window into the team's sensemaking process. If the plots are inaccurate, they could reflect an unhealthy team process and may encourage CDO intervention.

\section{Team Dynamics}

The findings suggest that teams also coordinate picture and plan building activities independent of technology. First, we recognized the need for all team members to contribute. The ship is only as safe as the lowest-ranking person who contributes to the picture and the highest-ranking person who maintains and communicates a higher-level view. Junior officers should contribute to the decision making process by providing forceful backup. They are trained to make recommendations which require analysis and articulation of the current situation, and planning. In addition, high ranking team members will make formal announcements to inform the team of their expectations and plans.

The researchers also found that members of a watch team may lack expertise, and may function at the outer boundary of their competency and other watch team members may be highly experienced. The variability in experience can be a potential barrier to information flow among watch team members. We interviewed one OOD that was able to overcome his lack of experience and the barrier to information flow by placing his focus on sharing knowledge and encouraging contributions.

Our findings also highlight the importance of training crisis-proof communication procedures. Communication procedures all need to be trained to automaticity. Once the behavior is skill based a team can share information effectively when situation complexity calls for Rasmussen's (1983) knowledge-based level thinking.

Finally, we learned the importance of having senior officers maintain a team monitoring role. CDO tension exists between the desire to become involved in the team sensemaking process, and the need to maintain a monitoring role and engage in independent sensemaking. If the CDO does not engage at the appropriate times he may jeopardize the ship and the mission. If the $\mathrm{CDO}$ engages at inappropriate times, he may lose sight of the big picture. This theme reflects tensions between strategic and tactical levels of thinking found in other domains (McHugh, Crandall \& Miller, 2006).

\section{CONCLUSIONS}

Control room digital plots support individual and team sensemaking, and are used as team health indicators. Also, the interactions among team members can be thought of as a team performance architecture that enables the essential work of building the picture and the plan, and executing the plan.

\section{ACKNOWLEDGMENTS}

The authors are grateful to the Office of Naval Research/Capable Manpower program manager Kip Krebs, contributors Jennifer McKneely, Megan Moundalexis, and William Lewis from Johns Hopkins University/Applied Physics Laboratory, and Donald Cox and Beth Crandall from Applied Research Associates. This material is based upon work supported by the Naval Sea Systems Command under prime contract number N00024-03-D-6606. Any opinions, findings, conclusions or recommendations expressed in the material are those of the authors and do not necessarily reflect the view of the Naval Sea Systems Command.

\section{REFERENCES}

Dominguez, C., McKneely, J., \& Fallon, C. K. (2008). Submarine systems development as a lens for CSE progress: Pushing the envelope of CSE methods. Published in Proceedings of the $52^{\text {nd }}$ Annual Meeting of the Human Factors and Ergonomics Society. New York, NY.

McHugh, A., Crandall, B., Miller, T. (2006). Barriers and Facilitators of Common Ground in Critical Care Teams. Published in Proceedings of the $50^{\text {th }}$ Annual Meeting of the Human Factors and Ergonomics Society. San Francisco, CA.

Rasmussen, J. (1983). Skills, rules, knowledge; signals, signs, and symbols, and other distinctions in human performance models. IEEE Transactions on Systems, Man and Cybernetics, 13, 257-266. 